\title{
Research on the Operation Strategy of Chain Convenience Stores under the Background of "New Retail"
}

\author{
Jingjing Liu \\ Business School, Wuhan Polytechnic, Guanshan Road, 463\#, Wuhan, China \\ 31909078@qq.com
}

\section{Keywords: New Retail; Chain Convenience Store; Operation; Strategy}

\begin{abstract}
Under the business background of "new retail", the integration of online, offline and modern logistics, coupled with the application of information technology such as big data and cloud computing, has brought in a new trend for the retail industry. The operation of chain convenience stores today is very different from the operation of traditional convenience stores. This paper explores the five main aspects of the differences and proposes five main strategies in businesses of chain convenience stores under the background of "new retail", can provide reference for the operation of chain convenience stores.
\end{abstract}

\section{Introduction}

In recent years, China's retail business market has undergone great changes. Under the background of the "Internet + ", the traditional retail industry was hit by e-commerce, and sales performance fell sharply. As the e-commerce business gradually declined due to lower user growth and web flow dividends, e-commerce sales growth slowed down and began to touch the "ceiling".

In this context, in October 2016, Ma Yun proposed the concept of "new retail" in the Computing Conference at Hangzhou, and said that the era of pure online e-commerce will soon end. The offline enterprises must go online, and the online enterprises must go offline, the "new retail" model of "online + offline + modern logistics" is the development trend of the retail industry.

The basic concept of "new retail" includes the following main aspects: First, the deep integration of "online + offline + logistics" aims to provide consumers with Omni-channel and comprehensive services; second, data technology drive, data technology is connected in each link of retail, and it shared online and offline data, to optimize retail efficiency. Third, the consumption-based retail essence is highlighted, and efforts are made to provide consumers with efficient and even more than expected services [1].

The "new retail" business model has brought a new trend to the retail business. Under the "new retail" background, offline retail stores will be different from traditional retail stores, and the operation of chain convenience stores also will change dramatically.

\section{The Development Status of China's Chain Convenience Stores Under the "New Retail" Background}

Chain convenience stores are different from large supermarkets and department stores. They are a retail format that meets the needs of customers for emergency and convenience. Its network coverage is wide, its location is closer to customers, and it can solve the "last mile" that the large supermarket cannot solve. It occupy an important position in the retail industry.

In the "2017 China Convenience Store Development Report", the convenience store industry grew at a rate of $13 \%$ in 2016, with a market size of more than 130 billion yuan. At the same time, the number of domestic convenience store brands has exceeded 260, and the number of stores is close to 100,000 . Compared to the number of convenience stores and the growth of convenience store sales, the average daily sales of convenience stores only increased $4 \%$, the competition is more intense. 
However, due to the large market space of this model, refined management still needs to be improved, and there still have space for improvement in profitability. Therefore, in the past two or three years, it has been favored by capital [2].

Under the "new retail" background, many well-known Internet companies have also laid out offline businesses and entered convenience stores market such as Taobao convenience store, Jingdong convenience store. Intelligent unstaffed convenience store such as Amazon Go, Bingo Box, and "new retail" convenience stores such as Bianlifeng are all appeared.

What are the differences between the "new retail" chain convenience stores and the traditional convenience stores under the "new retail" business model?

\section{The Difference Between "New Retail" Chain Convenience Stores and Traditional Convenience Stores}

Compared with the traditional convenience store, the "new retail" chain convenience store mainly has the following five differences:

Business Model Differences. The business model of traditional convenience store is operating offline store and mainly to meet the convenience and timely demand of customers to earn sales profit. It is more concerned about the sales and profitability of the offline stores.

The "new retail" chain convenience store is a deep integration of "online + offline + modern logistics", while expanding online and offline business, providing customers with "online purchase - offline delivery/door to door delivery"、 "offline ordering and online deliver "service methods, provide Omni-channel and comprehensive services.

The online channels include the self-operated e-commerce platform, WeChat, the third-party platform such as the Meituan.com, etc., so that it has the convenience of offline sales and the rich, low-cost, distribution service experience of one-stop shopping for online sales.

Its aim is to make maximize sales and profit of the whole chain store and even the whole supply chain.

Target Customer Group Differences. The customer groups of traditional convenience stores are mainly offline consumer groups. Their consumption characteristics are mainly based on timely demand. While enjoying convenient services, they pay attention to service quality and experience.

The target customers of the "New Retail" convenience chain stores include online and offline customer groups. The online shopping group has certain planned needs, and is also dominated by young groups. They are good at price comparison online, like one-stop shopping, and pay attention to product reputation, brand and quality. They pay attention to the types of products such as environmental protection and health, original ecological, pollution-free, natural non-additive, organic, and non-GMO products.

Differences in the Goods in Sales. The goods sold in traditional convenience stores are mainly the goods on the store shelves, while the "new retail" chain convenience stores can sell all kinds of goods on the physical store and online platform, which greatly enriches the categories of goods.

Differences in Logistics Distribution Mode. The sales mode of traditional convenience store is mainly the customer-to-store and choose-by-yourself. The logistics distribution mode is that the goods are distributed from the suppliers or distribution center to the store. The store always stores a certain number of goods, and the customer picks up the goods at the store.

The "new retail" chain convenience store has more complicated distribution mode. Because of its online business, it has the pre-position storage function of the e-commerce platform, which can realize online shopping and fast delivery to the customer as its geographical advantage close to the customer. For example, Tmall.com online supermarket has combined with convenience stores and express delivery companies to achieve one-hour delivery to your home.

Differences in Payment Methods. The traditional convenience store mainly uses the POS terminal to receive pay. The customers can pay by cash, bank card or membership card.

Self-service shopping and mobile payment are often used in "new retail" convenience stores. At present, there are two main payment methods: the first one is the highest-end and most convenient 
payment-free method. At present, only Amazon Go, Take Go and Tao coffee can be realized; the second is the most common scanning payment method in the market [3]. Mobile payments have become the main form of payment.

\section{"New Retail" Chain Convenience Store Business Strategy}

From the above analysis, we can see there are big differences between the "new retail" chain convenience store and the traditional convenience store from the business model to the target customer group, and the actual operation. Then, under the "new retail" business model, what business strategy should the chain convenience store to adopt to operate better?

The specific strategies are as follows:

Strengthen the Guide Function of Offline Stores. That means making full use of the geographical advantages that near final customers of offline stores.

Firstly, we need to improve the customer experience in offline store. The strategies include create a good brand image, make a quality service guarantee, make the brand and goods recognized and so on. Obtain customers and then lead customers to online shopping. Usually the higher the offline recognition, the larger the customer volume, the greater the online sales, they are generally proportional.

Offline products can be diverted with differentiated products and services. Provide popular products based on the target customer groups of the store. If the location of the store is near a residential area, school, or office building, then the target customer groups are not the same, the customer demands are different. The fresh food demand in the residential area is large, and the school surrounding areas are need fast food, fruit (cutting and packing), and stationery. There is a large demand for best-selling supplementary books, newspapers and magazines, etc. Shops near the office building need to provide fresh food, coffee, breakfast, fast food, staying up late, fresh, fruit (cutting and packing), etc., to provide dining space.

The following are also the main methods to guide customers, such as renting umbrellas, sharing charging treasures, selling magazines, children's products, parcel collection, laundry collection, microwave heating, free boiling water, free printing and copying, and transportation card recharge. Some convenience stores even have a book corner, which not only can guide, but also extend the stay time of customers in the store and enhance the customer's culture and leisure experience.

Reasonable Setting the Goods Categories of Online and Offline. Usually, convenience stores have a limited area, generally within 100 square meters, and offline SKU products about 3,000SKU, while online products can be expanded to tens of thousands or even hundreds of thousands. If you can set online and offline products categories according customer demand characteristics, it will greatly improve business performance.

To properly set up online and offline merchandise categories, firstly, you must maximize the benefits of the limited number 3,000SKU varieties offline. Therefore, offline stores should sell goods with high convenience, high passenger attraction capacity, large circulation, and hot-selling goods. For example, as the core of the convenience store's product structure, fresh food etc., and traditional standardized products, planned demand products are sold online.

To achieve the suitable product categories, it is necessary to use information systems, big data analysis, to analysis customer consumption data, and accurately grasp the customer's demand characteristics. Selecting products that are more meet the needs of users in the life circle around each store, maintaining a high rate of store product updates, updating the shelf display, and constantly close to the needs of users.

Optimize Logistics and Supply Chain Systems. Convenience stores need to establish a logistics supply system supported by new technologies, new resources and big data. Through logistics and supply chain optimization, they can improve operational efficiency, ensure continuous supply of goods, reduce shortage of goods, and reduce operating costs. Market demand can also be responded quickly. 
Intelligent ordering. Using information system, based on the accumulated sales status and surrounding environment, combined with daily weather, promotional information and major festivals, the demand of goods in a single store can be measured accurately, and the system automatically gives the store staff the number to order. At the same time, the store manager can make optimization adjustments based on personal operating experience to help the system to continuously learn and predict more accurately.

Optimize inventory management. The goal of inventory management is to reduce inventory as much as possible, speed up inventory turnover, and increase order fulfillment rates in stores, thereby reducing order costs, inventory costs, and out-of-stock costs.

In optimizing inventory management, it is necessary to classify and manage according the uncertainty of the demand of the commodity itself and the size of the commodity circulation. As shown in Fig. 1.

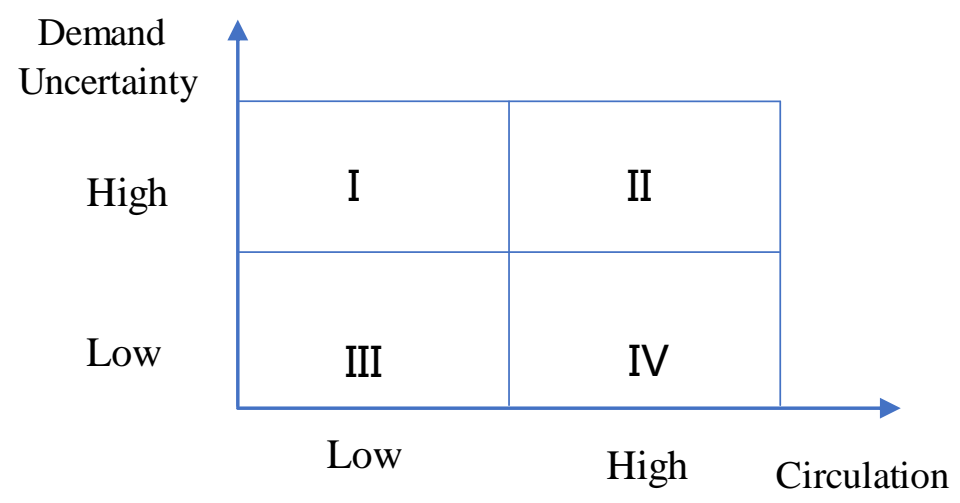

Figure 1. Commodity categories according demand uncertainty and circulation

In I and II quadrants, the commodities have high demand uncertainty. High demand uncertainty means high-risk. In order to reduce the inventory of each single store, we can centralized store these goods in the distribution center, and then deliver the inventory when there is a clear demand information. The risk sharing principle can be used to effectively offset the volatility of demand.

The circulation speed of the goods in II quadrant are higher than the goods in I quadrant, so they need more safety stock. And the best way to replenish goods in II quadrant is to establish partnerships with suppliers and use quick respond policy.

In III quadrant, the commodities have relatively low demand uncertainty and liquidity. To minimize inventory costs, they can be stored and replenished according the long-term forecasts data, that is, using a push supply chain.

In IV quadrant, the goods have low demand uncertainty, that is, products with relatively stable demand. And the circulation speed is high. Such goods can directly store in convenience stores, improving distribution efficiency and customer service levels, and reducing out-of-stock losses.

For high-level or price-sensitive products, can use the way of pre-sale or delayed delivery to reduce inventory. The use of pull supply chain can reduce inventory, reduce capital backlog, lower unit price (e-commerce users prefer online comparison), and improve competitiveness.

To physical convenience stores, the occasional shortage of goods has little effect, because customers may choose alternatives, or even lost sale this time, most customers will come back next time. But it is different in online purchase. If online users want to buy the goods but they are out of stock, the experience will be very poor. To do online and offline operations, accuracy inventory needs are very high. Therefore, in terms of data, it is necessary to specify the inventory level of each store, which requires a large adjustment and upgrade in the entire operation system of the convenience store.

Optimize the logistics distribution system. Efficient, low-cost, low-traffic distribution system is the guarantee of operation. Different products use different delivery methods.

There are three main types of distribution methods: instant delivery, Distribution Center store and then distribution, and direct delivery from suppliers. Products with high circulation rates, such 
as beverages in the summer, can be directly transferred to the distribution center in large quantities for immediate delivery. General merchandise can be delivered to the distribution center first, and then delivered to the store according the order quantity of the store. Some goods that are not convenient for multiple transfer can also be directly delivered to the store by the supplier.

Products that need temperature control need to use the Internet of Things technology to monitor the whole process, so that the cold chain logistics can guarantee the quality.

Work closely with suppliers to strengthen synergies. Through big data analysis, the store can accurately grasp the market demand, achieve rapid response to market demand, improve the overall operational efficiency of the supply chain, and form a competitive advantage.

Supplier collaboration strategies, such as shared terminal sales information, supplier managed inventory, and supplier replenishment, can also be used to enhance collaboration with suppliers and improve the efficiency of the entire supply chain.

The Use of Convenient Payment Methods. The "new retail" convenience stores can improve the service experience by using convenient payment methods. Currently, the commonly used scan code payment is to download and install the app, and then make self-service shopping and self-service payment, and there is no need to wait in line.

Mobile payments promote the development of traditional retail in physical stores. Mobile payment can create a more flexible and intimate consumer environment for consumers, realize the electronic and mobile wallets, greatly enrich user-selectable payment methods, and facilitate users.

At the same time, by paying big data, customers' preferences and consumption habits data can be collected, and the merchant can further optimize the consumption experience and upgrade the commercial elements of the new retail.

Strengthen Employee Training. The "new retail" convenience stores have high customer service requirements, online and offline sales channels, different types of online and offline products, and diversified payment methods. All these require a certain service experience. The clerk's professional appearance, service attitude, business ability, especially the experience of shopping and dealing with customer dissent, are all directly affect the customer's experience. These aspects need to strengthen training.

Experienced clerk should be able to guide and dig out the needs of customers, quickly and reasonably answer and deal with customer objections, and win repeat customers.

Besides the five aspects of the strategies above, the "new retail" convenience stores also have more business strategies can apply, such as the use of big data to analysis the location of the store, analysis the consumption data to adjustment store's business strategy, as well as doing research on the relationship of local people's consumption habits, lifestyle and the characteristics of the store.

\section{Conclusion}

Under the "new retail" background, with the integration of online and offline sales channels, the upgrading of modern logistics distribution systems, the widespread use of big data and information technology, the operation of chain convenience stores has changed greatly compared with the traditional model. Only to face the differences correctly, and to adopt targeted business strategies, such as strengthen the guide function of offline stores, reasonably set up commodity categories online and offline, optimize supply chain logistics systems, adopt easy-to-use payment methods, and enhance employee training. These strategies will enable convenience stores to develop their strengths better, operate more efficiently and achieve better development.

\section{References}

[1] Wang Baoyi, The Essence, Cause and Practice of "New Retail", China's Circulation Economy. 2017, 31 (07), pp. 3-11.

[2] $\mathrm{Ma} \mathrm{Li}$, Convenience store Business strategy Explore under the "new retail" market, The National Circulation Economy, 2017(10), pp.3-4.

[3] Information on http://www.mpaypass.com.cn/news/201710/12100459.html 
[4] Li Fung Research Center, Supply Chain Management - Practice of Hong Kong Li Fung Group (Second Edition), Renmin University of China Press, 2009, pp.261-263. 